\title{
Effect of Valdecoxib on transitional pain after elective ambulatory surgery
}

Authors: N Imasogie (FRCA), G Foster (FRCA), L Froste (RN), S Ganapathy (FRCPC), Affiliations: Dept of Anesthesia and Peri-operative Medicine, St Joseph's Health Care, University of Western Ontario, London.

\section{INTRODUCTION}

Transitional pain is defined as the pain that occurs following the recession of regional anesthesia. Shoulder surgery is associated with severe pain for the first 24-48 hours. Opioid analgesics currently used to manage transitional pain can be both inadequate and have undesirable sideeffects. Valdecoxib a new COX-2 inhibitor can improve analgesia. Our objective was to evaluate the analgesic efficacy of Valdecoxib following brachial plexus block.

\section{METHODS}

Following IRB approval,60 adults of either gender between the ages of 18-75 (ASA I-III), scheduled for elective ambulatory shoulder surgery and regional analgesia were to be randomized into two groups. Group 1 were given Valdecoxib $40 \mathrm{mg}$ orally 1 hour before surgery and thereafter $40 \mathrm{mg} 12$ hourly for three days. Group 2 were given Placebo 1 hour before surgery and thereafter 12 hourly for three days.

All patients received acetaminophen 1 gm q 6 hourly for three days. Patients were provided with Oxycodone and told to take 5-10 mg 4 hourly as required. All patients were provided Dimenhydrinate for nausea and vomiting. All patients received sedation for the block( fentanyl and midazolam) and a general anesthetic for the procedure. Peri-operative doses of narcotics used were recorded. Interscalene block was performed using $40 \mathrm{ml}$ of $0.5 \%$ ropivacaine with epinephrine 1:400,000.

Pain VAS scores were recorded preoperatively, postoperatively and in a patient diary once a day on a $100 \mathrm{~mm}$ scale. The patient also recorded time block receeded, how much oxycodone was required daily, and how much gravol was used daily. The patient sent the diary back to the researchers for analysis.

\section{RESULTS}

A total of 11 patients $(2 \mathrm{~F}, 9 \mathrm{M})$ have been randomized so far. Six were given Valdecoxib and 5 received placebo. One woman was admitted and the second did not return the diary.

\begin{tabular}{|l|l|l|l|l|l|l|l|l|l|l|}
\hline Study No & $\begin{array}{l}\text { Age } \\
\text { (yrs) }\end{array}$ & ASA & M/F & $\begin{array}{l}\text { VAS } \\
\text { In } \\
\text { PACU }\end{array}$ & $\begin{array}{l}\text { Fent } \\
\text { (Micro- } \\
\text { gm) }\end{array}$ & $\begin{array}{l}\text { Morph } \\
(\mathrm{mg})\end{array}$ & $\begin{array}{l}\text { Period of } \\
\text { analg } \\
\text { (hrs) }\end{array}$ & $\begin{array}{l}\text { Oxyc- } \\
\text { tot. } \\
\text { (no. } \\
\text { tabs) }\end{array}$ & $\begin{array}{l}\text { Average } \\
\text { Post-op } \\
\text { VAS } \\
\text { R/M }\end{array}$ & gravol \\
\hline $0001(\mathrm{~V})$ & 55 & 2 & $\mathrm{M}$ & $0 / 0$ & 150 & 0 & 12.5 & 6 & $16 / 25$ & 3 \\
\hline $0002(\mathrm{P})$ & 24 & 1 & $\mathrm{M}$ & $0 / 0$ & 200 & 0 & 10 & 4 & $42 / 47.5$ & 1 \\
\hline $0003(\mathrm{P})$ & 32 & 1 & $\mathrm{M}$ & $11 / 50$ & 100 & 8 & 8 & 25 & $59.5 / 79.5$ & 0 \\
\hline $0004(\mathrm{~V})$ & 58 & 3 & $\mathrm{M}$ & $0 / 0$ & 250 & 0 & 8 & 0 & $9.7 / 23$ & 0 \\
\hline $0006(\mathrm{~V})$ & 59 & 2 & $\mathrm{M}$ & $0 / 0$ & 150 & 0 & 12.5 & 0 & $5.2 / 7$ & 0 \\
\hline $0009(\mathrm{~V})$ & 59 & 2 & $\mathrm{M}$ & $0 / 28$ & 500 & 10 & 13 & 5 & $0 / 4$ & 3 \\
\hline $0010(\mathrm{P})$ & 74 & 2 & $\mathrm{M}$ & $42 / 26$ & 350 & 0 & 5.5 & 17 & $44 / ?$ & 0 \\
\hline $0011(\mathrm{P})$ & 39 & 1 & $\mathrm{M}$ & $0 / 0$ & 250 & 0 & 10 & 26 & $37.5 / 62.5$ & 0 \\
\hline $0012(\mathrm{~V})$ & 64 & 2 & $\mathrm{M}$ & $0 / 0$ & 150 & 0 & 9.5 & 8 & $16 / 16$ & 0 \\
\hline
\end{tabular}


Legend: VAS, $\mathrm{R} / \mathrm{M}=$ at rest/ on movement, Morph=morphine, Oxyc tot.=Total oxycodone tabs taken during whole study, VAS Average.= average of VAS scores from day 0 to day 3 postop.

The lowest pain scores occurred in patients who had Valdecoxib. The average number of oxycodone tablets taken per patient was 18 in the placebo group versus 3 in the Valdecoxib group. Both patients who did not require any oxycodone were in the Valdecoxib group.

\section{CONCLUSION}

Valdecoxib does significantly lower peri-operative use of opioids and leads to lower VAS scores for transitional pain. 